\title{
Endometriosis-associated Malignancy
}

\author{
Endometriose-assoziierte Malignome
}

Authors

Affiliations
N. Krawczyk ${ }^{1}$, M. Banys-Paluchowski ${ }^{1,4}$, D. Schmidt ${ }^{2}$, U. Ulrich ${ }^{3}$, T. Fehm ${ }^{1}$

${ }^{1}$ Department of Obstetrics and Gynecology, University of Düsseldorf, Düsseldorf

2 Synlab MVZ Pathologie Mannheim GmbH, A2, 2, Mannheim

${ }^{3}$ Department of Obstetrics and Gynecology, Martin Luther Hospital, Berlin

${ }^{4}$ Department of Obstetrics and Gynecology, Marienkrankenhaus Hamburg, Hamburg

\begin{abstract}
Key words
- endometriosis

- ovarian cancer

- endometriosis-associated malignancy

- atypical endometriosis

- malignant transformation

Schlüsselwörter

- Endometriose

- Ovarialkarzinom

- Endometriose-assoziierte Malignome

- atypische Endometriose

- maligne Transformation
\end{abstract}

\section{Abstract \\ $\nabla$}

Endometriosis is a common condition in women of reproductive age. According to several epidemiological studies endometriosis may be associated with increased risk of various malignancies. However, endometriosis-associated malignancy (EAM) is defined by certain histological criteria. About $80 \%$ of EAM have been found in the ovary, whereas $20 \%$ are localized in extragonadal sites like intestine, rectovaginal septum, abdominal wall, pleura and others. Some authors suggest that EAM arise from atypical endometriosis as an intermediate lesion between endometriosis and cancer. Moreover, a number of genetic alterations, like loss of heterozygosity (LOH), PTEN, ARID1 A and p53 mutations have been found in both endometriosis and EAM. Endometriosis-associated ovarian cancer (EAOC) is mostly a well or intermediately differentiated tumor of endometrioid or clear cell histological sub-type. Women affected by EAOC are on average five to ten years younger than non-EAOC patients; in most of the cases EAOC is a low stage disease with favorable clinical outcome. Since EAM is a rare condition systematic data on EAM are still missing. A systematic retrospective study on endometriosis-associated malignancies (EAM study) is currently being conducted by the Endometriosis Research Foundation together with the study groups on ovarian and uterine tumors of the working group for gynecological oncology (AGO) (gyn@mlkberlin.de).

\section{Zusammenfassung \\ $\nabla$}

Endometriose stellt eine häufige, gutartige Erkrankung der Frau im reproduktiven Alter dar. Epidemiologischen Studien zufolge gibt es eine Assoziation zwischen Endometriose und dem Risiko, an verschiedenen Malignomen zu erkranken. Die Diagnose von endometrioseassoziierten Malignomen (EAM) kann jedoch erst nach Erfüllen einiger histologischer Kriterien erfolgen. Circa $80 \%$ der EAM entstehen im Ovar, während in $20 \%$ der Fälle eine primär extragonadale Manifestation möglich ist (Darm, rektovaginales Septum, Bauchwand, Pleura u.a.). Eine der Entstehungstheorien besagt, dass EAM direkt aus der atypischen Endometriose entstehen. Darüber hinaus wurden bis dato zahlreiche Mutationen wie PTEN-, ARID1 A- oder p53-Mutationen sowie Heterozygotieverlust sowohl in der Endometriose als auch in EAM nachgewiesen. Ein endometrioseassoziiertes Ovarialkarzinom (EAOC) stellt meist ein gut oder mittelgradig differenziertes Karzinom vom endometroiden oder klarzelligen Typ dar. EAOC-Patientinnen sind durchschnittlich 5-10 Jahre jünger als Frauen mit Nicht-EAOC; in den meisten Fällen wird das EAOC im frühen Stadium diagnostiziert und hat eine günstige Prognose. Aufgrund des seltenen Auftretens der EAM liegen in der Literatur nur wenige systematische Studien zu dieser Entität vor. Eine retrospektive Studie zur Charakterisierung endometrioseassoziierter Malignome (EAM-Studie) wird aktuell von der Stiftung Endometrioseforschung gemeinsam mit den Kommissionen Ovar und Uterus der Arbeitsgemeinschaft Gynäkologische Onkologie (AGO) durchgeführt (gyn@mlk-berlin.de). 
Table 1 Epidemiological studies on association between endometriosis and ovarian cancer.

\begin{tabular}{|c|c|c|c|c|c|}
\hline Author & Type of study & $\begin{array}{l}\text { Number of } \\
\text { endometriosis cases }\end{array}$ & $\begin{array}{l}\text { Number of } \\
\text { cancer cases }\end{array}$ & $\begin{array}{l}\text { Number of } \\
\text { controls }\end{array}$ & $\begin{array}{l}\text { OR, SIR, HR or RR } \\
(95 \% \mathrm{Cl})\end{array}$ \\
\hline Brinton 1997 [8] & cohort & 20686 & 29 & & $1.92(1.3-2.8)$ \\
\hline Ness 2000 [10] & case control & 66 (85 CG) & 767 & 1367 & $1.7(1.2-2.4)$ \\
\hline Ness 2002 [11] & case control & 51 (39 CG) & 5207 & 7705 & $1.73(1.10-2.71)$ \\
\hline Olson 2002 [12] & cohort & 1392 & 3 & & $0.78(0.25-2.44)$ \\
\hline Brinton 2004 [13] & cohort & 12193 & 45 & & $2.48(1.3-4.2)$ \\
\hline Borgfeldt and Andolf 2004 [14] & nested case control & 28163 & 81 & 84489 & $1.34(1.03-1.75)$ \\
\hline Modugno 2004 [15] & case control & 177 (184 CG) & 2098 & 2953 & $1.32(1.06-1.65)$ \\
\hline Melin 2006 [16] & cohort & 64992 & 122 & & $1.43(1.19-1.71)$ \\
\hline Melin 2007 [17] & cohort & 63630 & 134 & & $1.37(1.14-1.62)$ \\
\hline Kobayashi 2007 [24] & cohort & 6398 & 46 & & $8.95(4.12-15.3)$ \\
\hline Pearce 2012 [18] & case control & 738 (818 CG) & 7911 & 13226 & $1.49(1.24-1.65)$ \\
\hline Stewart 2012 [22] & cohort & 2978 & 38 & & $2.33(1.02-5.35)$ \\
\hline Buis 2013 [23] & cohort & 3657 & 34 & & $12.4(2.8-54.2)$ \\
\hline Kok 2015 [20] & cohort & 2266 & 13 & & $4.56(1.72-12.11)$ \\
\hline
\end{tabular}

CG: control group, RR: relative risk, OR: odds ratio, HR: hazard ratio, SIR: standardized incidence ratio

\begin{tabular}{ll}
\multicolumn{2}{l}{ Abbreviations } \\
CCC & Clear cell carcinoma \\
DFS & Disease-free survival \\
EAM & Endometriosis-associated malignancy \\
EAOC & Endometriosis-associated ovarian cancer \\
HR & Hazard ratio \\
LOH & Loss of heterozygosity \\
OC & Ovarian cancer \\
OR & Odds ratio \\
OS & Overall survival \\
PTEN & Phosphatase and tensin homolog \\
RR & Relative risk \\
SIR & Standardized incidence ratio
\end{tabular}

\section{Introduction}

Endometriosis is a common condition in women in which endometrium-like tissue is detected outside the uterine cavity [1]. The incidence of the disease in females of reproductive age is estimated at 5 to $15 \%$ [2]; the main symptoms are dysmenorrhea, pelvic pain and infertility [3]. Despite extensive research in this field, the exact pathogenesis of endometriosis remains not fully understood but one widely accepted hypothesis is the implantation of endometrial tissue in the peritoneal cavity due to retrograde menstruation [4]. Although endometriosis is considered a benign condition, it has been demonstrated to share some characteristics with malignant tumors such as tissue invasion and damage, neoangiogenesis or spread to distant organs [5]. Current knowledge about endometriosis-associated malignancies will be presented in this review.

\section{Endometriosis and Cancer Risk - Epidemiological Data $\nabla$}

According to several epidemiological studies endometriosis is associated with increased risk of various malignancies with the best evidence for ovarian cancer [6-18]. Furthermore, a number of cohort and case control studies demonstrated an epidemiological association of endometriosis with endometrial cancer, breast cancer, colorectal cancer, non-Hodgkin lymphoma and others [8, $19,20]$. The clinical significance of the association between endometriosis and non-gynecologic malignancies is poorly understood [21].

The majority of the published studies on endometriosis-associated ovarian cancer have reported that ovarian cancer (OC) risk among endometriosis patients is moderately increased (RR, SIR or OR 1.32-1.92) ( 0 Table 1). The strongest association between $\mathrm{OC}$ and endometriosis was reported by Brinton et al. $(\mathrm{SIR}=2.48)$ [8], Stewart et al. [22] $(\mathrm{HR}=2.33)$ and Buis et al. [23] $(\mathrm{HR}=12.4)$; interestingly, these three studies included only women suffering from infertility, which may be a potential confounding factor for their results. Moreover, a remarkably high increase of ovarian cancer risk ( $S I R=8.95$ ) has been demonstrated by Kobayashi et al. [24]. In their retrospective cohort study ovarian cancer risk was analysed in women with sonographically diagnosed endometriomas based on time periods from first diagnosis of endometrioma to first diagnosis of ovarian cancer. Since endometriomas were histologically confirmed in only one-third of the cases, whereas the majority of diagnoses was made based on ultrasound image, the ovarian cancer risk has been possibly overestimated in this analysis: some of ovarian cysts identified as endometriomas might have been in fact ovarian cancers. In summary, there are a number of epidemiological studies, in which at least a modest association between endometriosis and ovarian cancer has been consistently demonstrated. Despite epidemiological evidence, a direct causal association between endometriosis and ovarian cancer has not been elucidated so far [25].

\section{Histological Findings}

The histological link between endometriosis and cancer has first been postulated as early as 1925 [26]. Sampson et al., based on microscopic observations, speculated that endometrial ovarian cancer may develop from endometriotic tissue and described the criteria for diagnosis of endometriosis-associated OC: (1) evidence of endometriosis close to the tumor, (2) exclusion of invasion from other sources, (3) presence of tissue resembling endometrial stoma surrounding characteristic epithelial glands [26]. Scott et al., in their analysis from 1953, added a fourth criterion: 
(4) histological proof of transition from benign changes in endometriosis to malignant changes in cancer [27]; all four criteria are still in use to define an endometriosis-associated malignancy (EAM).

About $80 \%$ of EAMs are localized in the ovary, whereas extragonadal sites are affected in one-fourth to one-fifth of all cases [9, 28]. In two large reviews of endometriosis-related neoplasms (222 and 205 cases, respectively), extragonadal tumors were reported in $21-24 \%$ of women $[29,30]$. Since the malignant transformation can take place in every site affected by endometriosis, extragonadal EAMs can be found in the lower pelvis, gastrointestinal tract, abdominal wall, umbilicus, pleura and others [31]. The most common localisations of extragonadal EAMs are the rectosigmoid, colon, rectovaginal septum and pelvic peritoneum; these sites are commonly involved by deep infiltrating endometriosis [31].

Based on histopathology and molecular features, ovarian cancers are divided into five main categories: high-grade serous, endometrioid, clear cell, mucinous, and low-grade serous carcinomas [32]. The most common subtype is the high-grade serous cancer (70\%), followed by the endometrioid (10\%) and clear cell (10\%) type. Endometrioid and clear cell carcinomas usually present as low-stage disease; the former is typically well differentiated [33]. Endometriosis-associated malignancies are most commonly cancers of these two histologic subtypes, rarely other ovarian malignancy types like borderline tumors, endometrial stromal sarcoma or adenosarcoma [18,25,28,31]. Recently published pooled analysis of case-controlled studies by Pearce et al. reported an increased risk for low-grade serous ovarian cancer among endometriosis patients as well (RR 2.11; 95\% CI 1.39-3.20, p<0.0001) [18]. No association between endometriosis and high-grade serous ovarian cancer or mucinous ovarian cancer has been reported to date $[18,28]$.

\section{Theories of Pathogenesis}

There are two main theories which attempt to explain the origin of endometriosis-associated malignancies. According to a number of histopathological studies endometriosis-associated ovarian cancer (EAOC) may arise from atypical endometriosis of the ovary [34,35]. This heterogeneous condition is histologically characterized by hyperplasia of endometrial glands with cytological atypia or presence of atypical hobnail cells within ovarian endometriosis [25, 36,37]. A direct association between atypical endometriosis and ovarian cancer was first demonstrated by La Grenade and Silverberg in 1988 [34]; in five cases of ovarian cancer (three clear cell carcinomas and two endometrioid carcinomas) accompanying atypical endometriosis was found in the ovary and in four out of five cases atypical changes were in contiguity with ovarian neoplasm [34]. Furthermore, a significantly higher rate of cytological atypia within endometriotic lesion was demonstrated in cases of EAOC compared with endometriosis alone [38]. Although the hypothesis that atypical endometriosis may be a premalignant condition is supported by the fact that it can be detected in up to $80 \%$ of EAOC, there are still not enough data proving this model $[35,39,40]$.

According to the other theory endometriosis is not a real precancerous lesion, but there is an indirect link involving common environmental, histological, immunological and genetic factors. Several studies have demonstrated that microenvironment of endometriosis and EAOC share similar mediators and cytokines [40,
41]. Whether EAM arise by malignant transformation of endometriotic cells through intermediary lesions (atypical endometriosis) or similarity of microenviroment represents a link between these both entities has not been definitely understood $[40,42]$.

\section{Genetic Alterations \\ $\nabla$}

In the last two decades, evidence has been accumulated that endometriosis-associated malignancies may arise within ovarian endometriosis. Possibly, periodic hemorrhage in ovarian endometriomas may lead to iron-triggered oxidative stress and thus induce genetic alterations. Yamaguchi et al. reported that the concentration of free iron in endometriotic cysts was over one hundred times higher than that in nonendometriotic cysts; the level of oxidative stress related markers, such as lactose dehydrogenase, and antioxidants was higher as well [43].

Accumulation of mutations in tumor suppressor genes and oncogenes is a crucial step during tumor development. Interestingly, numerous mutations in genes linked to carcinogenesis have been identified in endometriotic lesions [44-52]. Several studies have reported genetic aberrations in tumor suppression genes, such as p53 and PTEN, in endometriosis specimens [53-55]. Inactivation of DNA mismatch repair genes through hypermethylation has been observed in endometriotic tissue as well [53]. Furthermore, genetic alterations associated with tumorigenesis are encountered more frequently in benign endometriosis samples from patients with synchronous ovarian cancer than in tumor-free patients who were diagnosed with endometriosis alone. Prowse et al. performed microsatellite analysis in ten patients with ovarian cancer and coexisting endometriosis; the tumor and endometriosis samples were analysed for common molecular genetic alterations [56]. 63 events of loss of heterozygosity ( $\mathrm{LOH}$ ) were detected in cancer specimens; one-third of these was also identified in the corresponding endometriosis samples, suggesting that endometriosis might be a clonal precursor to a subtype of ovarian cancer. Hypothetically, endometriosis-associated and endometriosis-independent ovarian cancer may develop through different molecular pathways with distinct genetic alterations ( $\bullet$ Table 2 ).

\section{Risk Factors}

$\nabla$

Several risk factors for EAM in patients with endometriosis have been reported to date. The size of endometrioma as well as postmenopausal status were demonstrated to be independent predictive factors for the development of ovarian cancer among endometriosis patients in the study by Kobayashi et al. [57]. In this prospective cohort trial which assessed the risk of ovarian cancer in 6398 women with ovarian endometriomas, tumor size $\geq 9 \mathrm{~cm}$ in diameter was shown to be associated with increased OC risk. However, as mentioned before, one of the limitations of this study is that endometriomas were diagnosed mostly by sonography, and therefore some of the larger tumors might in fact have been ovarian cancers [57]. Another risk factor for EAM is hyperestrogenism, both endo- and exogenous: in the study by Zanetta et al. obesity as well as therapy with unopposed estrogens after hysterectomy were shown to be a significant risk factor for the development of EAM [58]. Similar effects of estrogen were demonstrated by others [40]. On the other hand, hormonal contraception, childbearing, tubal ligation or hysterectomy were found 
Table 2 Genetic alterations associated with endometriosis and endometriosis-related malignancies.

\begin{tabular}{|c|c|c|}
\hline Factor & $\begin{array}{l}\text { Genetic } \\
\text { alteration }\end{array}$ & Current data \\
\hline $\begin{array}{l}\text { Oxidative } \\
\text { stress }\end{array}$ & 8-OHdG & $\begin{array}{l}\text { 8-Oxo-2'-deoxyguanosine is a marker of oxidative DNA damage. Endometriosis-related ovarian cancer show significantly } \\
\text { stronger staining of 8-OHdG than ovarian cancers not accompanied by endometriosis [43]. Endometriotic cysts and atyp- } \\
\text { ical endometriosis also stain positive for this marker. 8-OHdG seems to play a role in pathogenesis of ovarian cancer and was } \\
\text { linked to poor prognosis [44]. }\end{array}$ \\
\hline \multirow[t]{3}{*}{$\begin{array}{l}\text { Tumor } \\
\text { suppressor } \\
\text { genes }\end{array}$} & PTEN & $\begin{array}{l}\text { Phosphatase and tensin homolog is mutated in many cancer entities, particularly in endometrial and endometrioid ovarian } \\
\text { cancer; its inactivation occurs early during tumorigenesis [53]. PTEN somatic mutations are frequently found in endo- } \\
\text { metriotic cysts [45]. }\end{array}$ \\
\hline & p53 & $\begin{array}{l}\text { As a negative cell-cycle regulator, } \mathrm{p} 53 \text { is involved in tumorigenesis of different malignancies. Several studies showed no } \\
\text { expression in benign endometriosis but high expression in benign endometriotic lesions next to the endometrioid or clear } \\
\text { cell carcinoma [54]. }\end{array}$ \\
\hline & ARID1A & $\begin{array}{l}\text { ARID1A mutations are significantly more common in two ovarian cancer subtypes associated with endometriosis (clear- } \\
\text { cell and endometrioid). In case of endometriosis synchronous with ovarian cancer, mutation was more frequent in clones } \\
\text { derived from endometriosis samples directly adjacent of the tumor than in those from distant endometriotic lesions [46]. }\end{array}$ \\
\hline DNA repair & hMLH1 & $\begin{array}{l}\text { hMLH1 corrects errors in DNA replication; hypermethylation of its promoter occurs early in endometrial malignant trans- } \\
\text { formation and can be identified in } 10 \% \text { of typical and in } 33 \% \text { of atypical endometrial hyperplasias [ } 47 \text { ]. Abnormal methyl- } \\
\text { ation can be observed in endometriosis as well [ } 53 \text { ]. }\end{array}$ \\
\hline \multirow[t]{2}{*}{ Oncogene } & $\mathrm{BCl}-2$ & $\begin{array}{l}\text { Expression of this anti-apoptotic protein is significantly higher in endometriosis accompanying cancer ( } 42-73 \%) \text { than in } \\
\text { benign endometriosis (23\%) [54], suggesting its role in the early steps of tumorigenesis. }\end{array}$ \\
\hline & KRAS & $\begin{array}{l}\text { KRAS mutations are significantly more common in endometriosis-associated endometrioid adenocarcinomas (29\%) than } \\
\text { in tumors not associated with endometriosis (3\%) [48]. }\end{array}$ \\
\hline $\begin{array}{l}\text { Chromosomic } \\
\text { aberrations }\end{array}$ & Aneuploidy & $\begin{array}{l}\text { Aneuploidic frequency seems higher in endometriosis specimen from patients with advanced endometriosis when com- } \\
\text { pared to the background frequency observed in normal specimens, particularly with regard to chromosome } 17 \text {, on which } \\
\text { tumor suppressor gene p53 is located }[49,50] \text {. }\end{array}$ \\
\hline $\begin{array}{l}\text { Loss of } \\
\text { heterozygosity } \\
\text { (LOH) }\end{array}$ & & $\begin{array}{l}\text { A trend of increasing } \mathrm{LOH} \text { frequencies has been described between solitary endometriosis lesions, endometriosis-associ- } \\
\text { ated carcinoma and endometrioid ovarian cancer, respectively }[51,52] \text {. Common LOH events can be identified in endo- } \\
\text { metriosis synchronous with ovarian cancer }[45,56] \text {. }\end{array}$ \\
\hline
\end{tabular}

to reduce the ovarian cancer risk among patients with endometriosis $[15,59]$.

\section{Clinical Implications}

EAOC is characterized by an early onset of the disease: Aris et al. reported in their retrospective cohort trial that the mean age of women with EAOC was $48.3 \pm 10.8$, on average 5.5 years lower than in non EAOC patients $(\mathrm{p}=0.003)$ [60]. In a retrospective study by Orezzoli et al. patients with endometriosis-associated clear cell cancer (CCC) of the ovary were even 10 years younger compared with those with non-endometriosis-associated CCC (95\% CI 0.6-18 years; $\mathrm{p}<0.05$ ) [61].

Interestingly, EAOC is commonly a low-stage and low-grade disease usually without ascites at initial presentation [62,63]. Furthermore, several authors reported that EAOC is associated with significantly better prognosis (DFS and OS) compared with nonEAOC, suggesting that EAOC represents a biologically distinct entity $[28,61,64,65]$. However, these findings have not been confirmed by others: after controlling for stage, age, grade and treatment no difference in overall survival between these two patient groups could be demonstrated $[62,66,67]$; thus, better clinical outcome of EAOC might be explained by a high rate of well-differentiated early-stage tumors rather than by an association with endometriosis per se $[62,63,67]$.

Based on existing data on incidence and risk factors of EAM, the possibility of malignant transformation should be included in diagnostic considerations for patients with endometriosis [21], especially in postmenopausal women who present a sudden recurrence of symptoms. Because of the malignant potential, endometriosis patients should, if indicated, receive a combined estrogen- progestin therapy (HRT, hormone replacement therapy) or tibolone even after hysterectomy; unopposed estrogens should generally be avoided in these patients $[21,68,69]$. Clinicians should be aware of the increased risk of specific subtypes of ovarian carcinoma in endometriosis patients. A modest increase in cancer risk should be discussed with these patients [70]. The risk of ovarian cancer is highest in women with endometriosis and primary infertility [13]. However, there are currently no diagnostic options to predict the risk of malignant transformation in an individual patient. Future studies should aim at understanding the mechanisms underlying this phenomenon so as to identify patients who are most at risk for developing endometriosis-related malignancy.

Since EAM are mostly low-grade tumors, there is the question of the efficacy of chemotherapy in EAOC patients [29]. However, in the study by Davis et al. no difference in response to chemotherapy in EAOC patients compared with controls with papillary serous ovarian cancer has been found [62]. Due to the lack of appropriate data postoperative treatment of EAOC follows the standard chemotherapy guidelines for ovarian cancer [71]. In case of extragonadal EAM, especially of rectum or rectovaginal septum, however, surgical resection followed by radiotherapy may be the treatment of choice $[29,31,65]$.

Several epidemiological studies, case reports and case series on EAM have been published in the literature to date. However, a systematic analysis of a large population of patients with EAM is still missing. Thus, a systematic retrospective study on endometriosis-associated malignancies (EAM study) is currently being conducted by the Endometriosis Research Foundation together with the study groups on ovarian and uterine tumors of the working group for gynecological oncology (AGO). Histopathological second opinion by pathology reference laboratory is the core 
component of this study (for more information: gyn@mlk-berlin. de).

\section{Conflict of Interest}

None.

\section{References}

1 Vignali $M$, Infantino $M$, Matrone $R$ et al. Endometriosis: novel etiopathogenetic concepts and clinical perspectives. Fertil Steril 2002; 78: 665-678

2 Sayasneh A, Tsivos D, Crawford R. Endometriosis and ovarian cancer: a systematic review. ISRN Obstet Gynecol 2011; 2011: 140310

3 Berkley KJ, Rapkin AJ, Papka RE. The pains of endometriosis. Science 2005; 308: 1587-1589

4 Gazvani R, Templeton A. New considerations for the pathogenesis of endometriosis. Int J Gynaecol Obstet 2002; 76: 117-126

5 Siufi Neto J, Kho RM, Siufi DF et al. Cellular, histologic, and molecular changes associated with endometriosis and ovarian cancer. J Minim Invasive Gynecol 2014; 21: 55-63

6 Ness RB. Endometriosis and ovarian cancer: thoughts on shared pathophysiology. Am J Obstet Gynecol 2003; 189: 280-294

7 Vercellini P, Parazzini F, Bolis G et al. Endometriosis and ovarian cancer. Am J Obstet Gynecol 1993; 169: 181-182

8 Brinton LA, Gridley G, Persson I et al. Cancer risk after a hospital discharge diagnosis of endometriosis. Am J Obstet Gynecol 1997; 176: 572-579

9 Heidemann $L N$, Hartwell D, Heidemann $C H$ et al. The relation between endometriosis and ovarian cancer - a review. Acta Obstet Gynecol Scand 2014; 93: 20-31

10 Ness RB, Grisso JA, Cottreau C et al. Factors related to inflammation of the ovarian epithelium and risk of ovarian cancer. Epidemiology 2000; 11: $111-117$

11 Ness RB, Cramer DW, Goodman MT et al. Infertility, fertility drugs, and ovarian cancer: a pooled analysis of case-control studies. Am J Epidemiol 2002; 155: 217-224

12 Olson JE, Cerhan JR, Janney CA et al. Postmenopausal cancer risk after self-reported endometriosis diagnosis in the Iowa Women's Health Study. Cancer 2002; 94: 1612-1618

13 Brinton LA, Lamb EJ, Moghissi KS et al. Ovarian cancer risk associated with varying causes of infertility. Fertil Steril 2004; 82: 405-414

14 Borgfeldt C, Andolf E. Cancer risk after hospital discharge diagnosis of benign ovarian cysts and endometriosis. Acta Obstet Gynecol Scand 2004; 83: 395-400

15 Modugno F, Ness RB, Allen GO et al. Oral contraceptive use, reproductive history, and risk of epithelial ovarian cancer in women with and without endometriosis. Am J Obstet Gynecol 2004; 191: 733-740

16 Melin A, Sparen P, Persson I et al. Endometriosis and the risk of cancer with special emphasis on ovarian cancer. Hum Reprod 2006; 21: 12371242

17 Melin A, Sparen P, Bergqvist A. The risk of cancer and the role of parity among women with endometriosis. Hum Reprod 2007; 22: 30213026

18 Pearce CL, Templeman C, Rossing MA et al. Association between endometriosis and risk of histological subtypes of ovarian cancer: a pooled analysis of case-control studies. Lancet Oncol 2012; 13: 385-394

19 Munksgaard PS, Blaakaer J. The association between endometriosis and ovarian cancer: a review of histological, genetic and molecular alterations. Gynecol Oncol 2012; 124: 164-169

20 Kok VC, Tsai HJ, Su CF et al. The risks for ovarian, endometrial, breast, colorectal, and other cancers in women with newly diagnosed endometriosis or adenomyosis: a population-based study. Int J Gynecol Cancer 2015; 25 : 968-976

21 Ulrich U, Buchweitz O, Greb R et al. Interdisciplinary S2k guidelines for the diagnosis and treatment of endometriosis: short version - AWMF Registry No. 015-045, August 2013. Geburtsh Frauenheilk 2013; 73: 890-898

22 Stewart LM, Holman CD, Aboagye-Sarfo P et al. In vitro fertilization, endometriosis, nulliparity and ovarian cancer risk. Gynecol Oncol 2013; 128: $260-264$
23 Buis CC, van Leeuwen FE, Mooij TM et al. Increased risk for ovarian cancer and borderline ovarian tumours in subfertile women with endometriosis. Hum Reprod 2013; 28: 3358-3369

24 Kobayashi H, Sumimoto K, Moniwa $N$ et al. Risk of developing ovarian cancer among women with ovarian endometrioma: a cohort study in Shizuoka, Japan. Int J Gynecol Cancer 2007; 17: 37-43

25 Schmidt D, Ulrich $U$. Endometrioseassoziierte Tumorerkrankungen des Ovars. Pathologe 2014; 35: 348-354

26 Sampson JA. Endometrial carcinoma of the ovary arising in endometrial tissue in that organ. Arch Surg 1925; 10: 1-72

27 Scott RB. Malignant changes in endometriosis. Obstet Gynecol 1953; 2 : 283-289

$28 \mathrm{Kim}$ HS, Kim TH, Chung HH et al. Risk and prognosis of ovarian cancer in women with endometriosis: a meta-analysis. Br J Cancer 2014; 110: 1878-1890

29 Heaps JM, Nieberg RK, Berek JS. Malignant neoplasms arising in endometriosis. Obstet Gynecol 1990; 75: 1023-1028

30 Irvin W, Pelkey T, Rice L et al. Endometrial stromal sarcoma of the vulva arising in extraovarian endometriosis: a case report and literature review. Gynecol Oncol 1998; 71: 313-316

31 Ulrich U, Rhiem K, Kaminski $M$ et al. Parametrial and rectovaginal adenocarcinoma arising from endometriosis. Int J Gynecol Cancer 2005; 15: $1206-1209$

32 Prat J. Ovarian carcinomas: five distinct diseases with different origins, genetic alterations, and clinicopathological features. Virchows Arch 2012; 460: 237-249

33 McCluggage WG. Morphological subtypes of ovarian carcinoma: a review with emphasis on new developments and pathogenesis. Pathology $2011 ; 43$ : 420-432

34 LaGrenade A, Silverberg SG. Ovarian tumors associated with atypical endometriosis. Hum Pathol 1988; 19: 1080-1084

35 Fukunaga $M$, Nomura $K$, Ishikawa $E$ et al. Ovarian atypical endometriosis: its close association with malignant epithelial tumours. Histopathology 1997; 30: 249-255

36 Clement $P B$. The pathology of endometriosis: a survey of the many faces of a common disease emphasizing diagnostic pitfalls and unusual and newly appreciated aspects. Adv Anat Pathol 2007; 14: 241-260

37 Seidman JD. Prognostic importance of hyperplasia and atypia in endometriosis. Int J Gynecol Pathol 1996; 15: 1-9

38 Prefumo F, Todeschini F, Fulcheri E et al. Epithelial abnormalities in cystic ovarian endometriosis. Gynecol Oncol 2002; 84: 280-284

39 Maiorana A, Cicerone C, Niceta M et al. Evaluation of serum CA 125 levels in patients with pelvic pain related to endometriosis. Int J Biol Markers 2007; 22: 200-202

40 Worley MJ, Welch WR, Berkowitz RS et al. Endometriosis-associated ovarian cancer: a review of pathogenesis. Int J Mol Sci 2013; 14: 5367-5379

41 Varma R, Rollason T, Gupta JK et al. Endometriosis and the neoplastic process. Reproduction 2004; 127: 293-304

42 Somigliana E, Vigano P, Parazzini F et al. Association between endometriosis and cancer: a comprehensive review and a critical analysis of clinical and epidemiological evidence. Gynecol Oncol 2006; 101: 331 341

43 Yamaguchi K, Mandai M, Toyokuni S et al. Contents of endometriotic cysts, especially the high concentration of free iron, are a possible cause of carcinogenesis in the cysts through the iron-induced persistent oxidative stress. Clin Cancer Res 2008; 14: 32-40

44 Pylvas M, Puistola U, Laatio L et al. Elevated serum 8-OHdG is associated with poor prognosis in epithelial ovarian cancer. Anticancer Res 2011; 31: 1411-1415

45 Sato N, Tsunoda H, Nishida M et al. Loss of heterozygosity on 10q23.3 and mutation of the tumor suppressor gene PTEN in benign endometrial cyst of the ovary: possible sequence progression from benign endometrial cyst to endometrioid carcinoma and clear cell carcinoma of the ovary. Cancer Res 2000; 60: 7052-7056

46 Wiegand KC, Shah SP, Al-Agha OM et al. ARID1A mutations in endometriosis-associated ovarian carcinomas. N Engl J Med 2010; 363: 1532 1543

47 Esteller M, Catasus L, Matias-Guiu Xet al. hMLH1 promoter hypermethylation is an early event in human endometrial tumorigenesis. Am J Pathol 1999; 155: 1767-1772

48 Stewart CJ, Leung Y, Walsh MD et al. KRAS mutations in ovarian lowgrade endometrioid adenocarcinoma: association with concurrent endometriosis. Hum Pathol 2012; 43: 1177-1183 
49 Shin JC, Ross HL, Elias S et al. Detection of chromosomal aneuploidy in endometriosis by multi-color fluorescence in situ hybridization (FISH). Hum Genet 1997; 100: 401-406

50 Simpson JL, Bischoff FZ, Kamat A et al. Genetics of endometriosis. Obstet Gynecol Clin North Am 2003; 30: 21-40, vii

51 Jiang X, Morland SJ, Hitchcock A et al. Allelotyping of endometriosis with adjacent ovarian carcinoma reveals evidence of a common lineage. Cancer Res 1998; 58: 1707-1712

52 Obata K, Hoshiai $\mathrm{H}$. Common genetic changes between endometriosis and ovarian cancer. Gynecol Obstet Invest 2000; 50 (Suppl. 1): 39-43

53 Martini M, Ciccarone M, Garganese G et al. Possible involvement of hMLH1, p16(INK4 a) and PTEN in the malignant transformation of endometriosis. Int J Cancer 2002; 102: 398-406

54 Nezhat F, Cohen C, Rahaman J et al. Comparative immunohistochemical studies of bcl-2 and p53 proteins in benign and malignant ovarian endometriotic cysts. Cancer 2002; 94: 2935-2940

55 Vigano P, Somigliana E, Chiodo I et al. Molecular mechanisms and biological plausibility underlying the malignant transformation of endometriosis: a critical analysis. Hum Reprod Update 2006; 12: 77-89

56 Prowse AH, Manek S, Varma $R$ et al. Molecular genetic evidence that endometriosis is a precursor of ovarian cancer. Int J Cancer 2006; 119: 556-562

57 Kobayashi H, Sumimoto K, Kitanaka T et al. Ovarian endometriomarisks factors of ovarian cancer development. Eur J Obstet Gynecol Reprod Biol 2008; 138: 187-193

58 Zanetta GM, Webb MJ, Li H et al. Hyperestrogenism: a relevant risk factor for the development of cancer from endometriosis. Gynecol Oncol 2000; 79: 18-22

59 Merritt MA, De Pari M, Vitonis AF et al. Reproductive characteristics in relation to ovarian cancer risk by histologic pathways. Hum Reprod 2013; 28 : $1406-1417$

60 Aris A. Endometriosis-associated ovarian cancer: a ten-year cohort study of women living in the Estrie Region of Quebec, Canada. J Ovarian Res 2010; 3: 2
61 Orezzoli JP, Russell AH, Oliva E et al. Prognostic implication of endometriosis in clear cell carcinoma of the ovary. Gynecol Oncol 2008; 110: 336-344

62 Davis M, Rauh-Hain JA, Andrade C et al. Comparison of clinical outcomes of patients with clear cell and endometrioid ovarian cancer associated with endometriosis to papillary serous carcinoma of the ovary. Gynecol Oncol 2014; 132: 760-766

63 Scarfone G, Bergamini A, Noli S et al. Characteristics of clear cell ovarian cancer arising from endometriosis: a two center cohort study. Gynecol Oncol 2014; 133: 480-484

64 Boyraz G, Selcuk I, Yazicioglu A et al. Ovarian carcinoma associated with endometriosis. Eur J Obstet Gynecol Reprod Biol 2013; 170: 211-213

65 Erzen M, Rakar S, Klancnik B et al. Endometriosis-associated ovarian carcinoma (EAOC): an entity distinct from other ovarian carcinomas as suggested by a nested case-control study. Gynecol Oncol 2001; 83: $100-108$

66 Melin A, Lundholm C, Malki N et al. Endometriosis as a prognostic factor for cancer survival. Int J Cancer 2011; 129: 948-955

67 Kumar S, Munkarah A, Arabi $\mathrm{H}$ et al. Prognostic analysis of ovarian cancer associated with endometriosis. Am J Obstet Gynecol 2011; 204: 63.e1-63.e7

68 Moen MH, Rees M, Brincat $M$ et al. EMAS position statement: Managing the menopause in women with a past history of endometriosis. Maturitas 2010; 67: 94-97

69 Soliman NF, Hillard TC. Hormone replacement therapy in women with past history of endometriosis. Climacteric 2006; 9: 325-335

70 Van Gorp T, Amant F, Neven P et al. Endometriosis and the development of malignant tumours of the pelvis. A review of literature. Best Pract Res Clin Obstet Gynaecol 2004; 18: 349-371

71 Ulrich $U$, Richter $O$, Wardelmann $E$ et al. [Endometriosis and malignoma]. Zentralbl Gynakol 2003; 125: 239-242 